FROM THE THIRD GENEVA CONFERENCE ON PERSON-CENTERED MEDICINE: THE
TEAM APPROACH IN PERSON-CENTERED HEALTH CARE

\title{
Person Centered Medicine and the Primary Care Team - securing continuity of care
}

\author{
Annemarie Uijen $\mathrm{MD}^{\mathrm{a}}$, Henk Schers MD PhD ${ }^{\mathrm{b}}$ and Chris van Weel MD PhD FRCGP \\ a Family Physician and Researcher \\ b Family Physician and Senior Researcher \\ c Professor of General Practice and immediate Past President, World Organisation of Family Doctors, \\ Department of Primary and Community Care, Radboud University Nijmegen Medical Centre, The Netherlands
}

\section{Keywords}

Continuity of care, information, integration, knowledge, multidisciplinary care, person-centered medicine, primary care team, responsiveness, uncertainty

\section{Correspondence Address}

Chris van Weel, Department of Primary and Community Care, Radboud University Nijmegen Medical Centre, 117-HAG, PO BOX 9101, 6500 HB Nijmegen, The Netherlands, E-mail: c.vanweel@elg.umcn.nl

Accepted for publication: 19 January 2011

\section{Introduction}

In the community, patients consult family physicians, nurses, physiotherapists, pharmacists and other allied health professionals for all the health problems that patients decide to present with. The principle of primary health care is that there is no operational selection of health problems, in terms of diagnosis, organ system, severity of patient category: it is for all patients, with all possible health problems, in all stages [1]. The everyday reality of primary health care is, nevertheless, that patients seek professional care for only a small minority (around $10 \%$ ) of the health problems they experience [2, 3] and most of these are treated within the primary care setting. As the community is where most of the people, with most of health problems are most of the time, it is the obvious place to promote health and prevention and to detect and manage diseases. This lends to primary health care its quintessential focus: that of individuals, who, in the context of their living and family environment, make contact for a variety of illness and disease, often over many years. This makes person-centered medicine a core characteristic of primary health care. This brings to primary health care the need to respond to individual reasons for contact and to do so consistently over time. Consistency is related to 'continuity of care' [4]. As primary health care is multidisciplinary in nature, the challenge for responsiveness and consistency is for the team and not only for the individual provider. Here, we analyse the role of 'responsiveness', 'continuity of care' and team work' in securing an approach that is centered on the person in the provision of (primary care) medicine.

\section{Responsiveness}

In the day to day business of primary health care, people usually initiate the contact for care, and present with a reason for that contact. The decision to visit a (family) physician, nurse or other primary health care professional, follows often from consultations of their family or 'trusted others' [3], and this makes it imperative to focus on the reason of why they come. Assessing the reason of why the patient comes is a key component of primary health care information, as defined by the International Classification of Primary Care [5]. Reasons for patients to contact can be - and often are - symptoms and complaints but 'reasons for encounter' are much broader than those understood by the traditional medical model of presented signs and symptoms [6, 7]. They include worries over their health, anxiety over a severe disease, a request for a diagnostic test or prescription, or the fact that it was an 'important other' in their environment that urged them to make contact. It is therefore imperative to start clarifying and addressing the reason of why the patient comes and understand the context in which care is provided [8].

This first step in this process requires an orientation on the person, and his/her family and socio-economic context. 
It helps an understanding of the patient's agenda and expectations and assists integration into the physician's agenda. Responding to the person's reason for contact emphasizes the need for interpersonal skills and directly enables patient empowerment. The successful outcome of the consultation therefore depends on all the above, without the (family) physician asserting an a priori control over what patients bring to the consultation. That is the domain of the patient and it forms part of the uncertainty that primary health care has to be able to deal with.

\section{Continuity of Care}

Continuity of care is an important feature of family practice. Health problems may vary, but the person of the patient remains the same. Continuity of care is valued by patients [9] and is positively related to health outcomes [10]. Continuity of care is often regarded as the frequency with which the patient is seen by the same health care provider - 'continuity in person' [11]. This emphasizes the person-centered dimension of continuity. But as good health care may occasionally require that patients are referred or admitted to hospital, this brings with it the need for continuity of information: for different providers involved in the care of the patient to share the same (person-specific) knowledge and information. This demonstrates the objective of continuity: to base health care on a person-centered framework of reference that is consistent over time and independent of the actual provider or the health problem at hand [12].

\section{Conclusion}

In the community, a number of health care disciplines have found their place: next to family physicians, there are midwifes, nurses, physiotherapists, dentists, psychologists, pharmacists, allied health professionals [13], and this extent of health care provision addresses, with social workers and pastoral workers, wellbeing as well as health. The needs of the community and also national and regional factors will determine which of these disciplines will actually be available in the community. The disciplines have in common that they are available for the variety of health problems that are experienced in the community and that they work with patients in the context of their everyday lives. This makes responsiveness and continuity of care shared values. Primary health care is in a transition from an individual to a team-based approach that operates in unison with people and communities. This makes it important to define common objectives for health care and common indicators with which to measure the team's achievements.

\section{References}

[1] Wonca Europe. The European definition of general practice/family medicine. Wonca Europe 2002. The European Definition of General Practice/Family Medicine (accessed April 17, 2010)

[2] Green L. A., Fryer, G. E., Yawn, B.P., Lanier D., Dovey, S. M. (2001). The ecology of medical care revisited. New England Journal of Medicine 344, 2021-25.

[3] van de Lisdonk E. H. (1989). Perceived and presented morbidity in general practice. Scandanavian Journal of Primary Health Care 7, 73-78.

[4] Campbell S. M., Roland M. O., Buetow S.A. (2000). Defining quality of care. Social Science and Medicine 51(11), 1611-1625.

[5] Wonca International Classification Committee. (1998). International Classification of Primary Care, ICPC-2. Second edition. Oxford, Oxford Press.

[6] Okkes I. M., Oskam S. K., Lamberts H. (2002). The probability of specific diagnoses for patients presenting with common symptoms to Dutch family physicians. Journal of Family Practice 51, 31-36.

[7] Lamberts, H., Brouwer, H. J., Mohrs, J. (1991) Reason for encounter, episode and process-oriented standard output from the transition project (two volumes). Department of General Practice/Family Medicine, University of Amsterdam.

[8] Di Blasi Z., Harkness E., Ernst E., Georgiou A., Kleijnen J. (2001). Influence of context effects on health outcomes: A systematic review. Lancet 357, 757-762

[9] Schers H., van de Ven C., van den Hoogen H., Grol R., van den Bosch W. (2004) Patients' needs for contact with their GP at the time of hospital admission and other life events: a quantitative and qualitative exploration. Annals of Family Medicine 2, 462468.

[10] Hanninen J., Takala J., Keinanen-Kiukaanniemi S. (2001) Good continuity of care may improve quality of life in Type 2 diabetes. Diabetes Research and Clinical Practice 51(1), 21-27.

[11] Freeman G. K., Olesen F., Hjortdahl P. (2003) Continuity of care: an essential element of modern general practice? Family Practice 20(6), 623-627.

[12] Uijen A. A., Schers H. J., van Weel C. (2010). Continuity of care preferably measured from the patient perspective. Journal of Clinical Epidemiology 63, publication in progress.

[13] WHO - Sixty-Second World Health Assembly. Primary health care, including health system strengthening. Geneva, WHO, WHA62.12. 